\title{
An Evaluation Method for Brittle Source of the Key Procedure in Complex Parts' Manufacturing
}

\author{
Ying Xiang, ${ }^{1,2}$ Rong Mo $\mathbb{D}^{2}, 2$ and Hu Qiao $\mathbb{D}^{3}$ \\ ${ }^{1}$ College of Mechanical and Electrical Engineering, Shaanxi University of Science and Technology, Xian, Shaanxi 710021, China \\ ${ }^{2}$ The Key Laboratory of Contemporary Design and Integrated Manufacturing Technology of Ministry of Education, \\ Northwestern Polytechnical University, Xian, Shaanxi 710072, China \\ ${ }^{3}$ School of Mechatronic Engineering, Xian Technological University, Xian, Shaanxi 710021, China
}

Correspondence should be addressed to Hu Qiao; qiaohu@xatu.edu.cn

Received 14 August 2017; Revised 21 December 2017; Accepted 25 December 2017; Published 28 January 2018

Academic Editor: Ivan Giorgio

Copyright (C) 2018 Ying Xiang et al. This is an open access article distributed under the Creative Commons Attribution License, which permits unrestricted use, distribution, and reproduction in any medium, provided the original work is properly cited.

\begin{abstract}
A method is proposed to analyze and evaluate brittle source of the key procedure in increasing the stability during complex parts' manufacturing. Based on the concept of machining cell, brittleness risk is introduced into the stability analysis of manufacturing process; the key procedure in manufacturing process is obtained by analyzing and calculating the brittleness risk entropy of each machining cell. Moreover, brittleness factors of the key process are analyzed to obtain a human-machine-environment brittleness model from man-machine-environment. The improved fuzzy analytic hierarchy process (FAHP) is used to analyze the relationship between the brittleness factor and the brittleness event, and a quantification method of the brittle factor in the key process is given. Thus, dangerous brittle sources in key procedure as well as abnormal control points for anomalies can be identified to improve the stability of complex parts' manufacturing processes. Finally, the correctness and effectiveness of this method are verified by using the manufacturing process of an aeroengine blade.
\end{abstract}

\section{Introduction}

In the study of complex parts' manufacturing process, stability is an important index, which is also an important factor to ensure product quality and productivity. Any scheduled tasks and objectives will become empty talk, if the stability of the equipment is not high in the manufacturing process, and, what is more, frequent failures and serious economic losses will be caused. Therefore, how to improve the stability of the manufacturing process has become a common problem faced by modern manufacturing enterprises [1].

The complexity of manufacturing system stability research is that there are extremely complex relationships between the devices in the system, where discrete events are not synchronized. At present, Petri net and its expansion method have become powerful tools to study the discrete event dynamic system and especially have made remarkable achievements in stability modeling and analysis of the manufacturing system [2-4]. But these methods neither have self-state changes caused by uncertain factors such as stress load, processing environment, artificial use conditions, and maintenance conditions during the service of the manufacturing system nor provide accurate, comprehensive, and quantitative analysis and evaluation of these influencing factors. The accident cannot be avoided accurately in the manufacturing process, while reducing the stability of the manufacturing system. Moreover, there is little qualitative analysis approach to improve the manufacturing process stability.

The research of system brittleness is a security problem to deal with interferences in the uncertain environment. That is, one or more subsystems of the system would collapse due to a small external interference. With the transmission and expansion of the collapse, the whole system will be collapsed. Brittleness risk is that the system brittleness is excited to collapses suddenly, which is caused by the uncertainty of the risk events of the external environment [5].

The United States Fouad proposed the concept of system brittleness firstly and has established transient energy function and an approach to analyze vulnerabilities of the neural 
network [6, 7]. In 2000, Albert et al. researched brittle source based on complicated theory; therefore, they brought the system brittleness into a new age [8]. Wang and Xu proposed a successor failure coupled map lattice model, which is a good mathematical method for cascading failures of the complex network $[9,10]$. Wei et al. had researched the system brittleness using the entropy and system mutation theory [11-13]. These studies focus on theoretical research and have established a study of the universality of all complex systems. Due to the complicacy and specificity of manufacture system, there are some differences in the study of brittleness with the common complex system. Qin et al. introduced brittleness theory of the complex system into the dynamic performance of complex process and analyzed quantitatively the factors that affect the quality dynamic performance of complex process $[14,15]$. Liu et al. proposed a stability analysis method of multistate manufacturing system based on brittleness theory by combining the complex brittleness theory with the multistate manufacturing system theory [16].

The brittleness of complex systems should be carefully studied to keep complex systems in good condition and to prevent from collapsing the whole manufacturing process because of the occurrence of brittle events. Due to the fact that manufacturing system has the hardware and software inherent flaws, external interference may cause irreparable failure of one or more of its subsystems, making the whole manufacturing system not able to work, which is called the brittleness of manufacturing system [17]. At the same time, there are different factors of mutual influence in a single machining unit; one or more factors may cause the machining unit to become abnormal in the process. Therefore, the complex part's manufacturing system is a complex system of collapse with brittle characteristics, and it is feasible that the brittleness theory is introduced into the manufacturing process to improve the stability of parts' manufacturing process.

As the basic element of the manufacturing process, procedure is a crucial impact for the stability of manufacturing process. A key procedure is the basis of improving the stability of manufacturing process, and the stability of key procedure, as an important node in manufacturing process, is ensured by analyzing impact factors of the key procedure. According to the characteristics of manufacturing process, such as complex structure of manufacturing, more fault source, and variable manufacturing tasks, the brittleness risk is explored in the stability analysis of manufacturing process by introducing the concept of machining cell [18] into this paper. On the basis of the research in the literature [19], this paper obtains the key procedure in the manufacturing process by analyzing and calculating the brittleness risk entropy of each machining cell. The human-machine-environment brittleness model is established by analyzing the brittleness factors of the key process from the man-machine-environment aspects. And then the approach of quantifying the brittleness of the key procedure is given from the improved fuzzy analytic hierarchy process (FAHP) to analyze the relationship between brittleness and brittle events [20-22] and to determine the dangerous brittle source of the key procedure. The control point of the abnormal key procedure is also determined from this method to provide theoretical support for improving the stability of complex parts' manufacturing process.

\section{The Characteristics of Complex Parts' Manufacturing}

Complex parts' manufacturing process includes the decomposition of manufacturing characteristics and the arrangements of the manufacturing process for the parts design model. As a carrier of parts' manufacturing information, manufacturing characteristics contain not only geometric topology information but also nongeometric information of manufacturing process, such as materials, hardness, tolerance, and surface quality. In general, characteristics can be divided into the following two categories.

(1) The Main Characteristic. It is used to build the geometric topology characteristics that are the overall structure of parts, which cannot be resplit, such as plane, cylinder, and hole.

(2) The Secondary Characteristic. It is the local geometry attached to main characteristics and is the local modification of the main structure, such as chamfering and keyway.

The complex parts' manufacturing process is composed of a number of object-oriented manufacturing characteristics according to their processing order and the relationship between one other. Beginning with the manufacturing characteristics, the parts' processing should be designed by combining parts materials, the relationship among characteristics, manufacturing resource, the design experience of technologist, and so forth. The complex parts' manufacturing process may be shown from parts, manufacturing characteristics, machining method, machining stage, and manufacturing resource in Figure 1.

Definition 1. Complex parts are made up by a number of manufacturing characteristics. For each manufacturing characteristic, it has to go through multiple processes generally to form a process (step) sequence that is called the machining chain. Each element in the machining chain is known as machining element expressed as

$$
U_{a b}=\left\{F_{a}, S_{b}, M_{c}, R_{d}\right\},
$$

where $F_{a}$ is the ath manufacturing characteristic, $a \in N$, and $N$ is total manufacturing characteristics; $S_{b}$ is the $b$ th machining stage belonging to $F_{a} ; M_{c}$ is the $c$ th machining method in $S_{b}$ belonging to $F_{a}$; and $R_{d}$ are manufacturing resources used in $S_{b}$ belonging to $F_{a}$.

The machining cell set, which is formed by each machining stage of all the characteristics on the part, can be expressed as $\mathbf{U}=\left\{U_{1 b}, \ldots, U_{i b}, \ldots, U_{N b}\right\}$; for easy expression, it can be expressed as $\mathbf{U}=\left\{u_{1}, \ldots, u_{i}, \ldots, u_{n}\right\}$, where $n$ is the total machining cell.

For machining cell, we have the following agreements:

(1) A machining cell has only one manufacturing characteristic, and it may be a procedure and also may be a process step. 


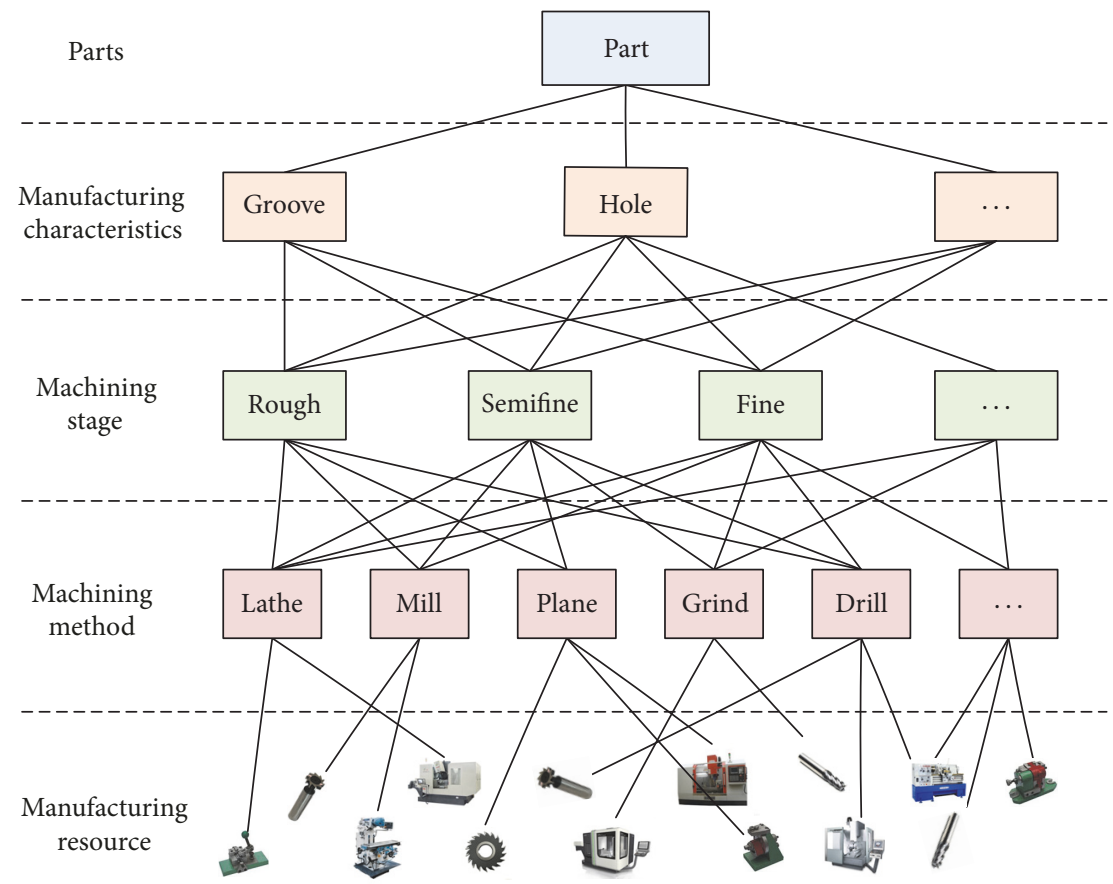

FIGURE 1: The hierarchical graph of parts' processing.

(2) A machining cell belongs to only one machining stage and one machining method.

(3) A machining cell uses only one machine and only one cutting.

In production, all machining cells form the step in accordance with certain rule; the roughcast can be processed between a step and another step in the driving of machining technology. Finally, the roughcast can become the product meeting the design requirement.

\section{The Key Procedure of the Complex Parts' Manufacturing Process}

The brittleness exists with the advent of complex systems. For the complex parts' manufacturing system, it has the hardware and software inherent flaws, which cause the whole manufacturing system not to work, because external interference may cause one or more of machining cells to fail to be repaired, which is the brittleness of machining cell.

Definition 2. In the manufacturing process, the procedure, which has the largest influence on the stability of the manufacturing system, is defined as key procedure.

Definition 3. The risk, of which the machining cell brittleness is excited, collapses suddenly to be defined as brittle risk of machining cell, which is caused by the uncertainty of the risk events from external environment.

Then the brittle risk of machining cell is analyzed to obtain the key procedure by grasping the probability in abnormal processing of the machining cell. That also lays the foundation for the analysis of brittle excitation factors of key procedure.

In manufacturing process of complex parts, brittle events of machining cell, caused by the processing personnel's lack of experience, equipment load, and so forth, may lead to failure of machining cell. Along with the transformation and expansion of the collapse behavior, the entire manufacturing process may be paralyzed. The brittle risk of complex parts' manufacturing is the risk of machining cell failure, because the brittleness of machining cell is excited. Then, it can be considered that the fundamental source of brittle risk of the entire parts' manufacturing process is the uncertainty of these brittle events.

The manufacturing system is made up based on the machining cells ordered relationship and their interconnected relationship. If the machining cell is regarded as a subsystem of the manufacturing system, it can be expressed as $S_{j}$, and the manufacturing system $S$ is composed of $n$ subsystems; that is, $S=\left\{S_{1}, S_{2}, \ldots, S_{n}\right\}$.

It is assumed that there is a brittle event $E=$ $\left\{E_{1}, E_{2}, \ldots, E_{v}\right\}$ in the subsystem $S_{j}$; the probability of the brittle event $E_{r}(r=1,2, \ldots, v)$ is $p_{r}$; there is a basic relation:

$$
\sum_{r=1}^{t} p_{r}=1, \quad 0 \leq p_{r} \leq 1 .
$$

Under the action of brittle event $E_{r}, q_{r}$ is a subsystem failure probability, and $0 \leqslant q_{r} \leqslant 1$. The subsystem failure probability $P_{S_{j}}$ caused by brittle events is shown as

$$
P_{S_{j}}=1-\prod_{r=1}^{t}\left(1-p_{r} q_{r}\right) \quad j=1,2, \ldots, n .
$$


In manufacturing system, the utilization coefficient, the subsystem $S_{j}$ failure effect system $S$ collapse, is defined as $\xi_{j}$.

The probability of the collapse of subsystem $S_{j}$ and the utilization coefficient are normalized to obtain the utilization coefficient of subsystem $S_{j}$ collapse:

$$
\begin{gathered}
g_{j}=\frac{P_{s_{j}} \xi_{j}}{\sum_{j=1}^{n} P_{s_{j}} \xi_{j}}, \\
\sum_{j=1}^{n} g_{j}=1, \quad 0 \leq g_{j} \leq 1 .
\end{gathered}
$$

Definition 4. According to Shannon theory [13], the brittle risk entropy $H(S)$ of subsystem $S_{j}$ is defined as the average of the risk probability of brittle event in the utilization coefficient space, expressed as

$$
H\left(S_{j}\right)=-g_{j} \log P_{s_{j}} .
$$

So,

$$
\begin{aligned}
H\left(S_{j}\right)= & -\frac{\left(1-\prod_{r=1}^{t}\left(1-p_{r} q_{r}\right)\right) \xi_{j}}{\sum_{j=1}^{n}\left(1-\prod_{r=1}^{t}\left(1-p_{r} q_{r}\right)\right) \xi_{j}} \\
& \cdot \log \left(1-\prod_{r=1}^{t}\left(1-p_{r} q_{r}\right)\right) .
\end{aligned}
$$

The brittle risk entropy is an uncertainty measure of possibility of subsystem brittleness occurrence. It may be used to judge brittle risk probability of subsystem at a given time, and it also may forecast the subsystem brittle risk.

The brittle risk entropy of each machining cell can be obtained by analyzing the brittle risk entropy of the subsystem. The lower the brittle risk entropy can be considered, the better the stability of machining cell is in the manufacturing process. By contrast, the higher the brittle risk entropy can be considered, the worse the stability of machining cell is in the manufacturing process. The key procedure in the manufacturing can be obtained by comparing the brittle risk entropy of each machining cell.

\section{The Man-Machine-Environment Brittleness Model of Brittle Excitation Factors in Key Procedure}

In manufacturing process of complex parts, a brittle excitation factor of key procedure may lead to the brittleness of machining cell, and it may affect other factors and stimulate some others. So, the brittleness of machining cell is excited by a variety of factors in manufacturing process. For example, the machine cutting speed is set too high, because technician lacks skills, which could lead to the thermal deformation of parts, rigid vibration, tool wear, positioning errors, and so forth. Thus, the processing element brittleness is excited. According to the factors analysis of brittle excitation in key procedure, the brittle excitation factors are attributed to each category by the degree of direct impact and indirect impact. Based on the machining cell, the brittle excitation factors of key procedure are analyzed from the man-machineenvironment system engineering, and those may be divided into three aspects:

(1) Personnel impact $V_{P}$, including the decision of management, the technology, character, and experience of operator

(2) Machine impact $V_{M}$, for example, the manufacturing resources, tools, and measuring tools

(3) Environment impact $V_{E}$, which mainly refers to the influence of other machining cells on this machining cell, including the processing characteristics influences that have been formed on the upper procedure and maybe also including other procedure influences that are the processing characteristics, positioning criteria, processing parameters, and so forth.

Thus, the brittle excitation factor set of the key procedure of manufacturing process is described as

$$
\begin{aligned}
V= & V_{P} \cap V_{M} \cap V_{E} \\
= & \left\{V_{e_{1}}, V_{e_{2}}, \ldots, V_{e_{p}}\right\} \cap\left\{V_{e_{p+1}}, V_{e_{p+2}}, \ldots, V_{e_{q}}\right\} \\
& \cap\left\{V_{e_{q+1}}, V_{e_{q+2}}, \ldots, V_{e_{u}}\right\} \\
= & \left\{V_{f_{1}}, V_{f_{2}}, \ldots, V_{f_{g}}\right\} \cap\left\{V_{f_{g+1}}, V_{f_{g+2}}, \ldots, V_{f_{h}}\right\} \\
& \cap\left\{V_{f_{h+1}}, V_{f_{h+2}}, \ldots, V_{f_{l}}\right\},
\end{aligned}
$$

where $V_{P}$ denotes the influence from man (personnel) in the machining cell, $V_{M}$ denotes the influence from machine in machining cell, and $V_{E}$ indicates that the machining cell is affected by other machining cells in manufacturing process.

$V_{P}=\left\{V_{e_{1}}, V_{e_{2}}, \ldots, V_{e_{p}}\right\}$ indicates that there are $p$ brittle excitation events in man aspect, $V_{M}=\left\{V_{e_{p+1}}, V_{e_{p+2}}, \ldots, V_{e_{q}}\right\}$ indicates that there are $q$ - $p$ brittle excitation event in machine aspect, and $V_{E}=\left\{V_{e_{q+1}}, V_{e_{q+2}}, \ldots, V_{e_{u}}\right\}$ indicates that there are $u-q$ brittle excitation event in environment aspect. Here, $u$ is the total number of brittle excitation events, where $1 \leqslant$ $p<u$ and $1 \leqslant q<u . l$ is the sum of the factors that affect the key procedure of the complex parts' manufacturing process, $\left\{f_{1}, f_{2}, \ldots, f_{g}\right\}$ indicates that there are $g$ brittle excitation factors in man aspect, $\left\{f_{g+1}, f_{g+2}, \ldots, f_{h}\right\}$ indicates that there are $h-g$ brittle excitation factors in machine aspect, and $\left\{f_{h+1}, f_{h+2}, \ldots, f_{l}\right\}$ indicates that there are $l-h$ brittle excitation factors in environment aspect, where $1 \leqslant g<l$ and $1 \leqslant h<l$.

\section{The Evaluation of Brittle Source in the Key Procedure}

The human-machine-environment model of brittle excitation factors in key procedure can be established, where the brittle excitation factors in key procedure are expressed through the use of complex system brittle structure, brittle events, and brittle factors, as shown in Figure 2. In the man-machineenvironment brittleness model, the brittleness of the key procedure is excited if the key procedure is out of control. 


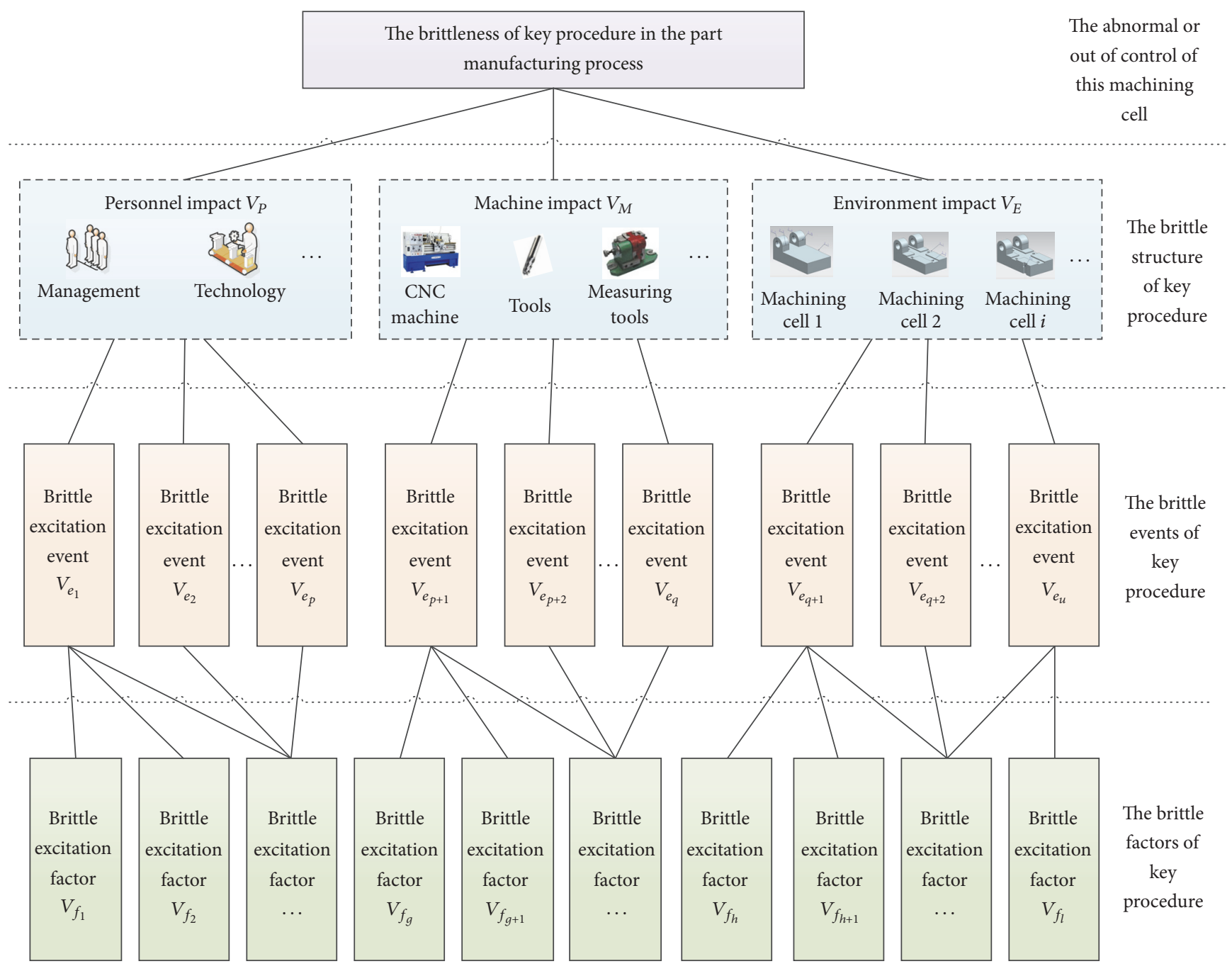

FIGURE 2: The human-machine-environment model of brittle excitation factors of key procedure in complex manufacturing process.

That is, the brittleness is that the machining cell fails in parts' manufacturing process, such as work piece deformation and unqualified processing size.

Due to the fact that the human-machine-environment model of brittle excitation factors in key procedure is hierarchical, the brittle source of key procedure may be analyzed and evaluated by using analytic hierarchy process.

Analytic hierarchy process (AHP), which is a decisionmaking approach, is a qualitative and quantitative approach proposed by Satty, a well-known American scientist, in 1977. AHP decomposes a complex problem into various constituent factors, which are grouped into the orderly hierarchical structure. The relative importance of many factors in the hierarchy is determined by the way of comparison; and then the total order of the relative importance of factors is determined by comprehensive judgment of people. Because the judgment matrix of AHP is difficult to achieve consistency and there is a difference between the consistency of the judgment matrix and the consistency of decision thinking, a fuzzy consistent matrix is introduced into the analytic hierarchy process to obtain a practical and effective fuzzy analytic hierarchy process (FAHP). The difference between fuzzy analytic hierarchy process and analytic hierarchy process is that the judgment matrix is fuzzy [23-25].

In this paper, an improved fuzzy analytic hierarchy process (FAHP) is used to convert the priority judgment matrix into a fuzzy consistency matrix, which satisfies the consistency condition and does not need to check the consistency of the judgment matrix. Furthermore, the initial ordering vector, as the eigenvalue of the iteration initial value, is obtained by using the square root method, which reduces the number of iterations to improve the convergence rate.

The steps evaluating brittle source based on the improved fuzzy hierarchy process are shown as follows.

(1) Stratify the Factors according to the Analysis. As shown in Figure 2, the highest level is the target, and the bottom is all brittle excitation factors.

(2) Constitute the Priority Judgment Matrix.

$$
\mathbf{E}=\left[e_{i j}\right]_{m \times m},
$$


TABLE 1: The scale method and definition of 0.1 to 0.9 .

\begin{tabular}{|c|c|}
\hline Scale & Definition \\
\hline 0.5 & A factor is equal to another factor \\
\hline 0.6 & $\begin{array}{l}\text { A factor is slightly more important than another } \\
\text { factor }\end{array}$ \\
\hline 0.7 & A factor is more important than another factor \\
\hline 0.8 & $\begin{array}{l}\text { A factor is much more important than another } \\
\text { factor }\end{array}$ \\
\hline 0.9 & $\begin{array}{l}\text { A factor is extremely more important than } \\
\text { another factor }\end{array}$ \\
\hline $0.1,0.2,0.3,0.4$ & Contrary \\
\hline
\end{tabular}

where $\mathbf{E}$ is a fuzzy complementary matrix and the matrix expresses the relative importance of each factor to the upper layer in each hierarchy; $e_{i j}$ is $0.1-0.9$ in the matrix usually. If the factor $i$ is as important as the factor $j, e_{i j}=0.5$; if the factor $i$ is more important than the factor $j$, then $e_{i j} \in(0.5,0.9]$; if the factor $j$ is less important than the factor $i$, then $e_{i j} \in$ $[0.1,0.5)$. Table 1 shows the 0.1 to 0.9 scale method and its definition.

(3) Constitute a Fuzzy Consistent Matrix. On the fuzzy judgment matrix $\mathbf{E}=\left[e_{i j}\right]_{m \times m}$, summarize by line

$$
r_{i}=\sum_{k=1}^{m} e_{i k}, \quad i=1,2, \ldots, m .
$$

And follow mathematical transformation:

$$
r_{i j}=\frac{r_{i}-r_{j}}{2 m}+0.5 \text {. }
$$

The priority judgment matrix is transformed into a fuzzy consistent matrix $\mathbf{R}=\left[r_{i j}\right]_{m \times m}$; the matrix $\mathbf{R}$ satisfies the consistency condition and does not need the consistency test.

By conversion formula $a_{i j}=r_{i j} / r_{j i}$, the matrix $\mathbf{R}$ is transformed into reciprocal matrix $\mathbf{A}=\left[a_{i j}\right]_{m \times m}$.

(4) Calculate the Relative Importance of Each Factor to a Factor in the Previous Level. The fuzzy consistency matrix is used to calculate the order of importance of each factor to a factor in the previous level, which can be calculated by using normalization, ranking method, and the square root method. This paper chooses the root method to guarantee the higher precision requirement.

$$
w_{i}=\frac{\sqrt[m]{\prod_{j=1}^{m} a_{i j}}}{\sum_{t=1}^{m} \sqrt[m]{\prod_{j=1}^{m} a_{t j}}} .
$$

The ranking vector $\mathbf{w}^{(0)}$ is as follows:

$$
\begin{aligned}
& \mathbf{w}^{(0)}=\left[\begin{array}{llll}
w_{1} & w_{2} & \cdots & w_{m}
\end{array}\right]^{T} \\
& =\left[\frac{\sqrt[m]{\prod_{j=1}^{m} a_{1 j}}}{\sum_{t=1}^{m} \sqrt[m]{\prod_{j=1}^{m} a_{t j}}} \frac{\sqrt[m]{\prod_{j=1}^{m} a_{2 j}}}{\sum_{t=1}^{m} \sqrt[m]{\prod_{j=1}^{m} a_{t j}}} \cdots \frac{\sqrt[m]{\prod_{j=1}^{m} a_{m j}}}{\sum_{t=1}^{m} \sqrt[m]{\prod_{j=1}^{m} a_{t j}}}\right]^{T},
\end{aligned}
$$

where $w_{1}, w_{2}, \ldots, w_{m}$ are the ranking weights.
The eigenvalue approach, using the permutation vector $\mathbf{w}^{(0)}$ as the iteration initial value $\mathbf{V}_{0}$, is used to obtain the highprecision sort vector $\mathbf{w}^{(k)}(k$ is the number of iterations). That is, we have the following:

(1) $\mathbf{V}_{0}=\left[\begin{array}{llll}v_{0,1} & v_{0,2} & \cdots & v_{0, m}\end{array}\right]^{T}$ is the iterative initial value; the characteristic vector $\mathbf{V}_{k+1}$ and the infinite norm $\left\|\mathbf{V}_{k+1}\right\|_{\infty}$ of $\mathbf{V}_{k+1}$ are obtained by using the formula $\mathbf{V}_{k+1}=\mathbf{A} \mathbf{V}_{k}$.

(2) Judgment: the maximum eigenvalue $\lambda_{\max }$ is $\left\|\mathbf{V}_{k+1}\right\|_{\infty}$ if $\left\|\mathbf{V}_{k+1}\right\|_{\infty}-\left\|\mathbf{V}_{k}\right\|_{\infty} \leq \varepsilon$, and then $\mathbf{V}_{k+1}$ will be normalized:

$$
\mathbf{V}_{k+1}=\left[\frac{v_{k+1,1}}{\sum_{i=1}^{m} v_{k+1, i}} \frac{v_{k+1,2}}{\sum_{i=1}^{m} v_{k+1, i}} \cdots \frac{v_{k+1, m}}{\sum_{i=1}^{m} v_{k+1, i}}\right]^{T} .
$$

The resulting vector is the final ranking vector. End.

(3) If not,

$$
\begin{aligned}
\mathbf{V}_{k} & =\frac{\mathbf{V}_{k+1}}{\left\|\mathbf{V}_{k+1}\right\|_{\infty}} \\
& =\left[\frac{v_{k+1,1}}{\left\|\mathbf{V}_{k+1}\right\|_{\infty}} \frac{v_{k+1,2}}{\left\|\mathbf{V}_{k+1}\right\|_{\infty}} \cdots \frac{v_{k+1, m}}{\left\|\mathbf{V}_{k+1}\right\|_{\infty}}\right]^{T} .
\end{aligned}
$$

As a new ranking vector, it is put into the next iteration.

(5) The Relative Importance of Each Factor to the Machining Cell Failure. The relative importance of each layer on the machining cell failure must be calculated from top to bottom.

Assume that the weight order vector, $n_{t-1}$ elements on the $t-1$ layer relative to the machining cell, has been calculated:

$$
\begin{aligned}
\mathbf{w} & (t-1) \\
= & {\left[\begin{array}{lllll}
\mathbf{w}_{1}^{(k)}(t-1) & \mathbf{w}_{2}^{(k)}(t-1) & \cdots & \mathbf{w}_{m_{t-1}}^{(k)}(t-1)
\end{array}\right]^{T} . }
\end{aligned}
$$

The weight ranking vector, the $m_{t}$ elements on the $t$ th layer for the $j$ th element on the $t-1$ layer, is set:

$$
\mathbf{p}_{j}(t)=\left[\begin{array}{lllll}
\mathbf{p}_{1 j}(t) & \mathbf{p}_{2 j}(t) & \cdots & \mathbf{p}_{m_{t} j}(t)
\end{array}\right]^{T},
$$

where the weight of the element not subject to $j$ is zero. Consider

$$
\mathbf{P}=\left[\begin{array}{llll}
\mathbf{p}_{1}(t) & \mathbf{p}_{2}(t) & \cdots & \mathbf{p}_{m_{t-1}}(t)
\end{array}\right] .
$$

This is an $m_{t} \times m_{t-1}$ matrix, which represents the order of the elements on the $t$-layer to the $t-1$ layer. Then, the synthetic ranking vector of each element on the $t$ th layer to the machining cell failure is given by

$$
\begin{aligned}
\mathbf{w}(t) & =\left[\begin{array}{lllll}
\mathbf{w}_{1}^{(k)}(t) & \mathbf{w}_{2}^{(k)}(t) & \cdots & \mathbf{w}_{m_{t}}^{(k)}(t)
\end{array}\right]^{T} \\
& =\mathbf{P}(t) \mathbf{w}(t-1) .
\end{aligned}
$$

Also,

$$
\mathbf{w}_{i}(t)=\sum_{j=1}^{m_{t-1}} \mathbf{p}_{i j}(t) \mathbf{w}_{j}^{(k)}(t-1), \quad i=1,2, \ldots, m .
$$


TABLE 2: Machining tasks of a blade.

\begin{tabular}{lccccc}
\hline Task & Machining task & $\begin{array}{c}\text { Machining } \\
\text { method }\end{array}$ & $\begin{array}{c}\text { Accuracy } \\
\text { class }\end{array}$ & $\begin{array}{c}\text { Surface } \\
\text { roughness Ra/ } \mu \mathrm{m}\end{array}$ & Note \\
\hline R6 & Blade top craft station & Milling & IT10 & 3.2 & Poor milling, CNC machining, special fixtures \\
R7 & Blade dorsal positioning surface & Milling & IT10 & 3.2 & Four-axis CNC machining, special fixtures \\
R8 & Tenon root & Wire cutting & IT10 & 3.2 & CNC wire-cutting machine, special fixtures \\
R9 & Positioning holes of craft station & Drilling & IT9 & 3.2 & Four-axis CNC machining, special fixtures \\
$\vdots$ & $\vdots$ & $\vdots$ & $\vdots$ & $\vdots$ & $\vdots$ \\
\hline
\end{tabular}

So,

$$
\mathbf{w}(t)=\mathbf{P}(t) \mathbf{P}(t-1) \cdots \mathbf{w}(2) .
$$

Here, $\mathbf{w}(2)$ is the ranking vector of the elements on the second layer to the machining cell failure.

From the fuzzy analytic hierarchy process, the total ranking of the hierarchy is actually given the relative importance of elements on a layer to the target layer. Thus, results of total ranking of the hierarchy can identify dangerous brittle sources of key procedure in complex parts' manufacturing processes, as well as the control points corresponding to the critical brittle sources of key procedure.

\section{Case}

The machining process of an aeroengine blade is taken as an example to verify the effectiveness of this approach [26]. In advanced blade machining center of engine manufacturers, there is great quantity advanced equipment, for example, fiveaxis CNC machine. According to the actual conditions of machining centers, the proposed approach is verified based on the aeroengine blade design requirements.

6.1. Obtaining the Key Procedure of a Blade Manufacturing Process. Due to the complexity of machining aerospace engine blades and limited space of this article, some of the manufacturing characteristics of the blade are taken as an example. The part of the manufacturing process and the required machining cell information of the leaf are shown in Table 2. Based on the design requirements of the aeroengine blade, manufacturing cost, and production approach, the reasonable process routes are obtained, in which the production cost and manufacturing time are the most reasonable [19, 27]. Formula (6) derives that the brittle risk entropy of machining cell (four-axis CNC machine milling blade dorsal positioning surface) is the highest in the aeroengine blade manufacturing process, as shown in Figure 3. The procedure, corresponding to the machining cell to the process, is a key process. How to calculate the brittle risk entropy of each machining cell has been described in detail in the article $[19,27]$; this paper will not repeat it.

6.2. The Human-Machine-Environment Model of Brittle Excitation Factors of Milling Blade Dorsal Positioning Surface. Based on the analysis of production factors and expert knowledge and formula (7), the brittle excitation factors of

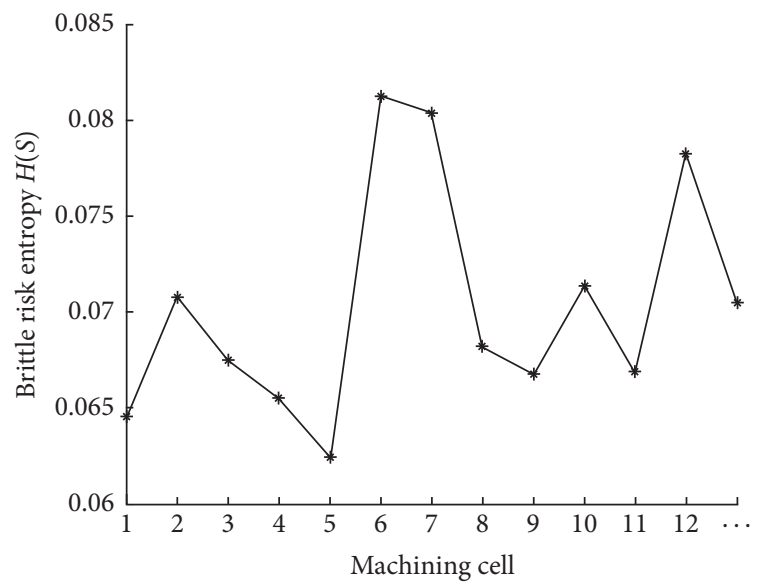

FIGURE 3: The brittle risk entropy of a part of machining cell.

milling blade dorsal positioning surface have been described as

$$
\begin{aligned}
V= & B_{P} \cap B_{M} \cap B_{E}=\left\{e_{1}, e_{2}\right\} \cap\left\{e_{3}, e_{4}, e_{5}\right\} \cap\left\{e_{6}, e_{7}\right\} \\
= & \left\{f_{1}, f_{2}, \ldots, f_{8}\right\} \cap\left\{f_{9}, f_{10}, \ldots, f_{19}\right\} \\
& \cap\left\{f_{20}, f_{21}, \ldots, f_{25}\right\},
\end{aligned}
$$

where the abnormity in the key procedure comes from brittle excitation event in man aspect (including the management errors and the operator error), brittle excitation event in machine aspect (including the CNC machine, tools, and measuring tools), brittle excitation event in environment aspect (including the previous procedure which is processing blade top craft station and the roughing processing of blade surface), and 7 brittle excitation events, brittle excitation factors in man aspect (lack of experience and skills and so on), brittle excitation factors in machine aspect (cutting speed being too high, the tool wear, and so on), brittle excitation factors in environment aspect (other machining cell processing precision and roughness and so on), and 25 brittle excitation factors.

According to the relationship between the brittle excitation factors of the milling blade dorsal positioning surface, the man-machine-environment brittleness model of milling blade dorsal positioning surface is constructed as shown in Figure 4 . 


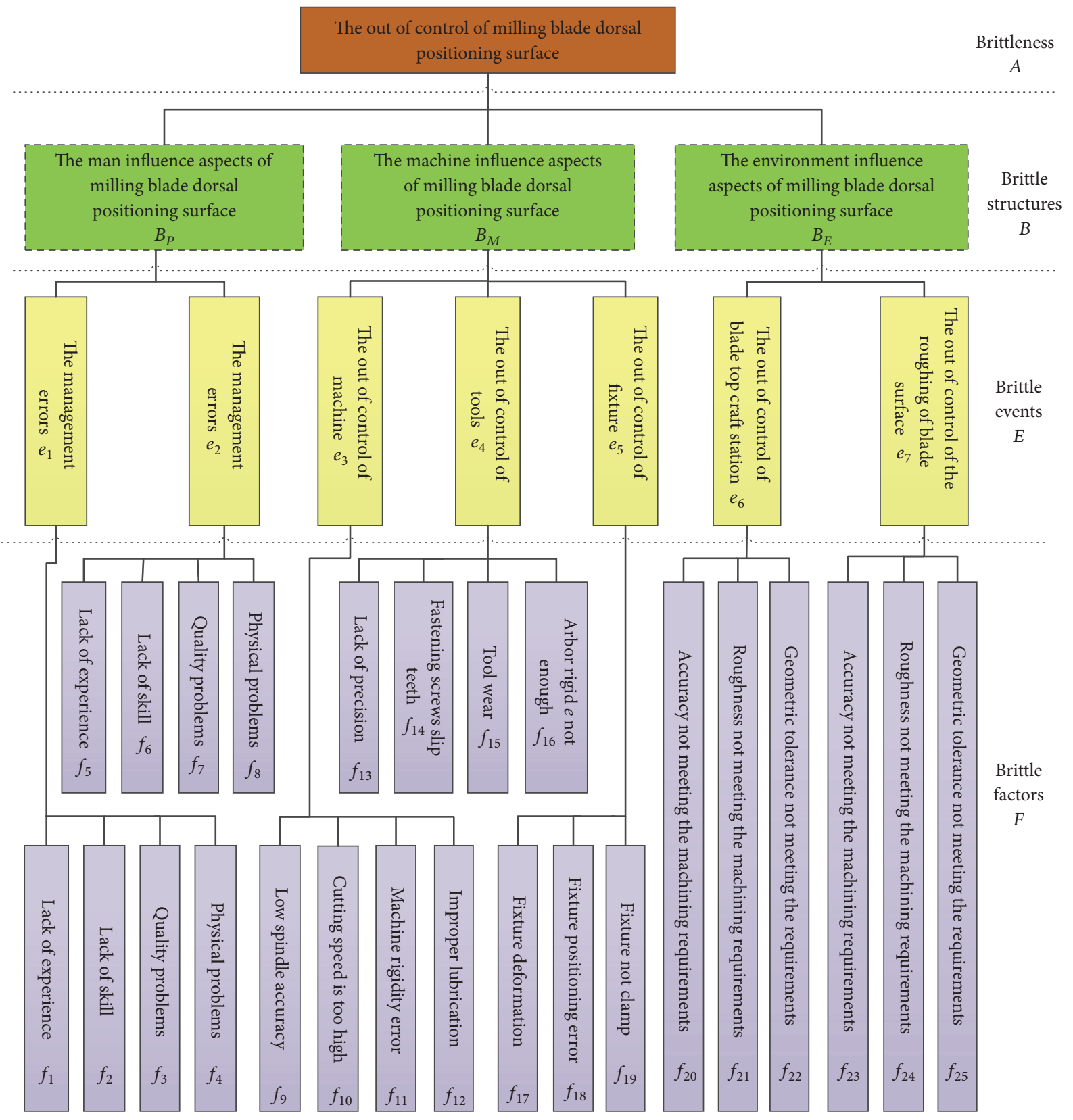

FIGURE 4: The man-machine-environment brittleness model of milling blade dorsal positioning surface.

In this model, abnormal processing of milling blade dorsal positioning surface is mapped as brittleness, the manmachine-environment influence aspects of milling blade dorsal positioning surface are mapped as brittle structures, the man-machine-environment influence events of milling blade dorsal positioning surface are mapped as brittle events, and the man-machine-environment influence factors of milling blade dorsal positioning surface are mapped as brittle factors.

6.3. Brittle Source Evaluation of Milling Blade Dorsal Positioning Surface. Combining the evaluating indicator of brittle source of milling blade dorsal positioning surface, the recommendations of the experts in the relevant field, and the judgement of the relative importance between two brittle excitation factors in Figure 4 together, there are 11 priority judgment matrices in the brittle source evaluation structure of milling blade dorsal positioning surface.

$$
\begin{gathered}
A-B\left[\begin{array}{lll}
0.5 & 0.1 & 0.5 \\
0.9 & 0.5 & 0.9 \\
0.5 & 0.1 & 0.5
\end{array}\right], \\
B_{P}-E\left(e_{1}, e_{2}\right)\left[\begin{array}{ll}
0.5 & 0.5 \\
0.5 & 0.5
\end{array}\right], \\
B_{M}-E\left(e_{3}, e_{4}, e_{5}\right)\left[\begin{array}{lll}
0.5 & 0.5 & 0.9 \\
0.5 & 0.5 & 0.9 \\
0.1 & 0.1 & 0.5
\end{array}\right],
\end{gathered}
$$




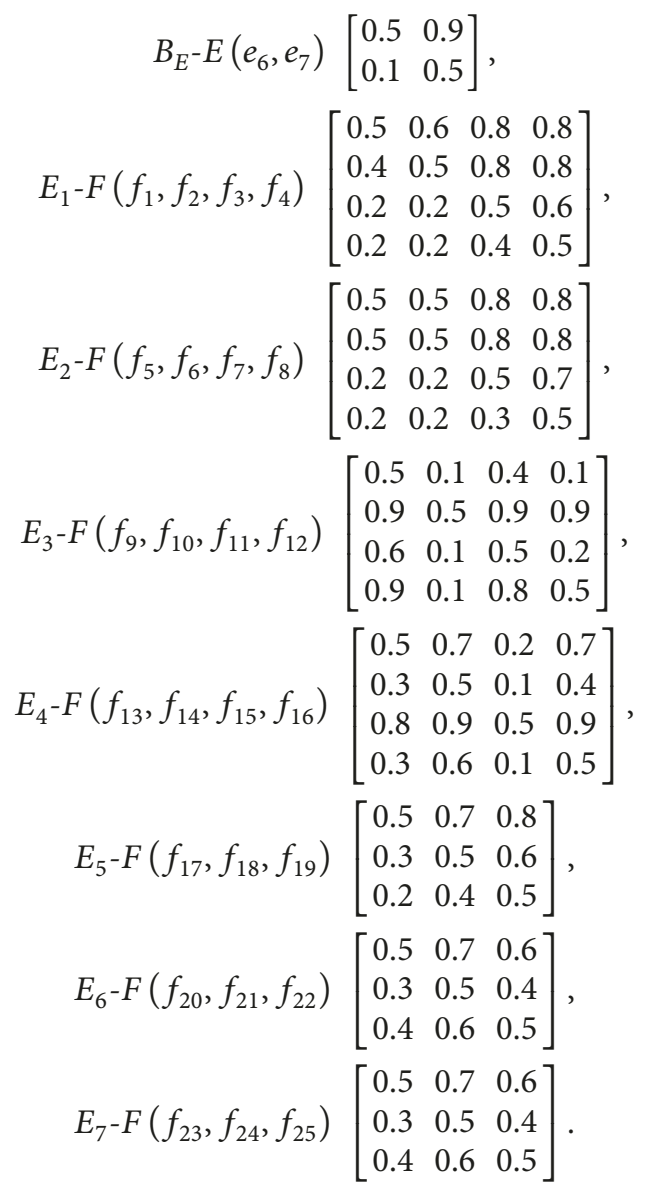

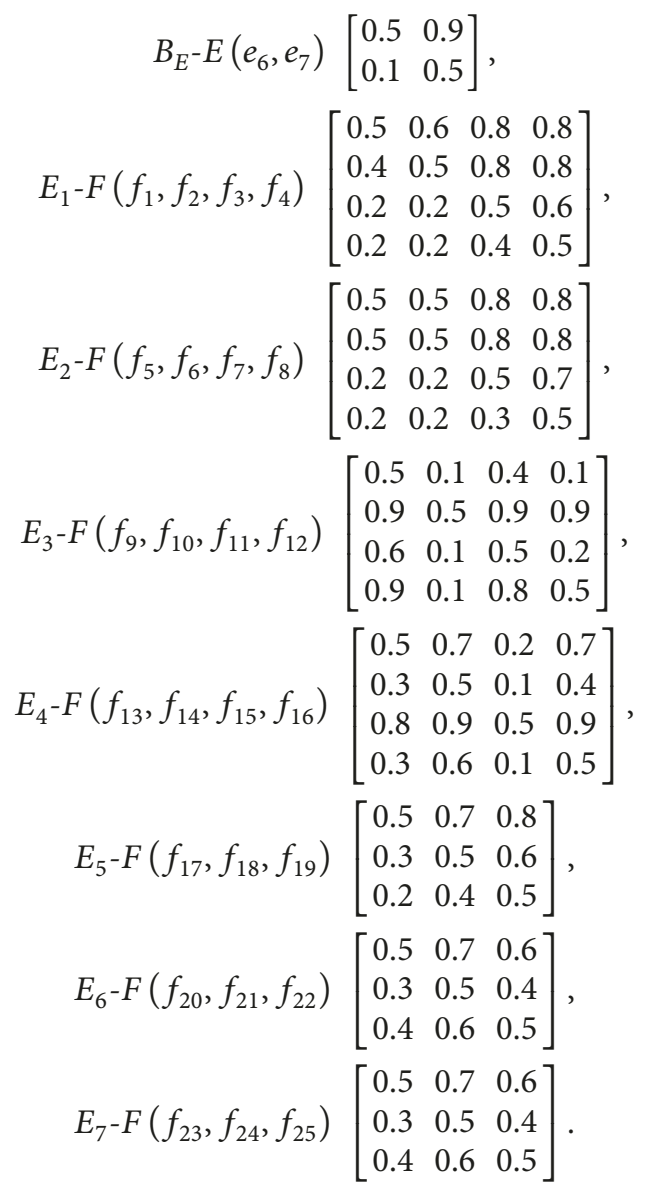

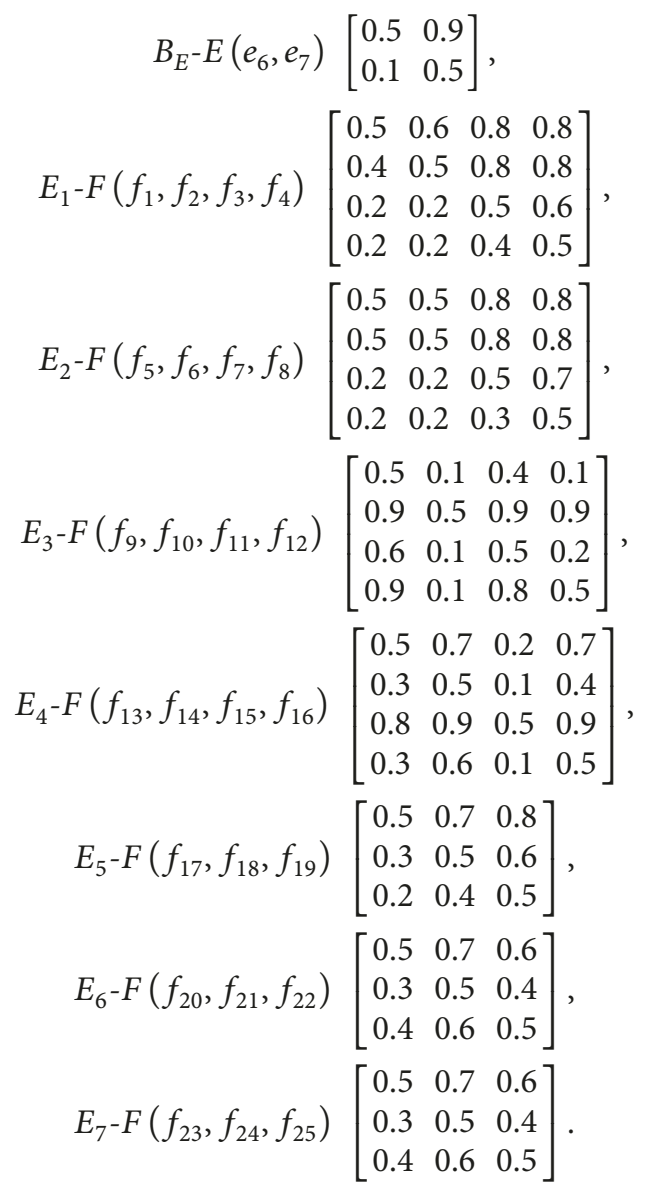

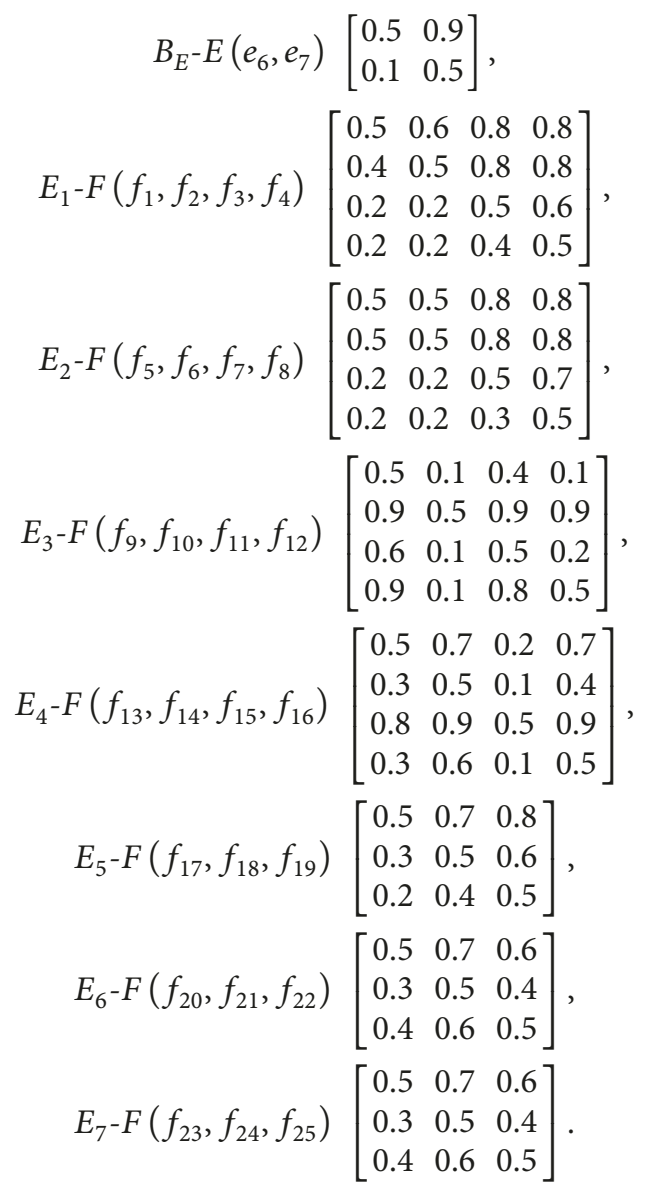

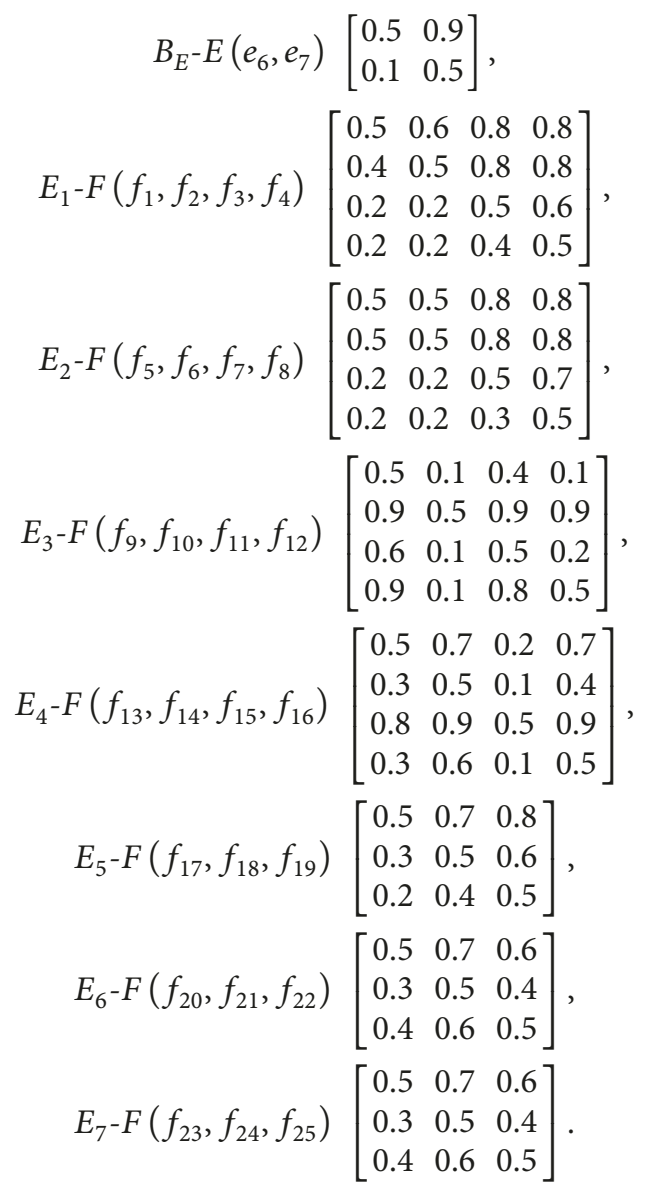

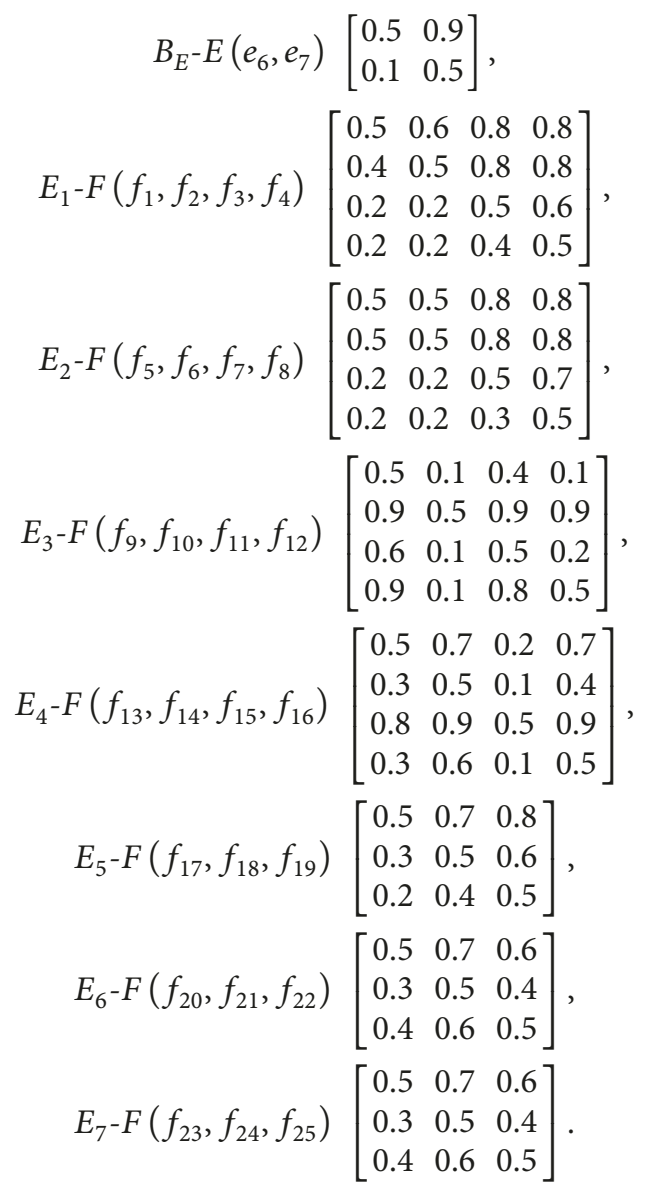

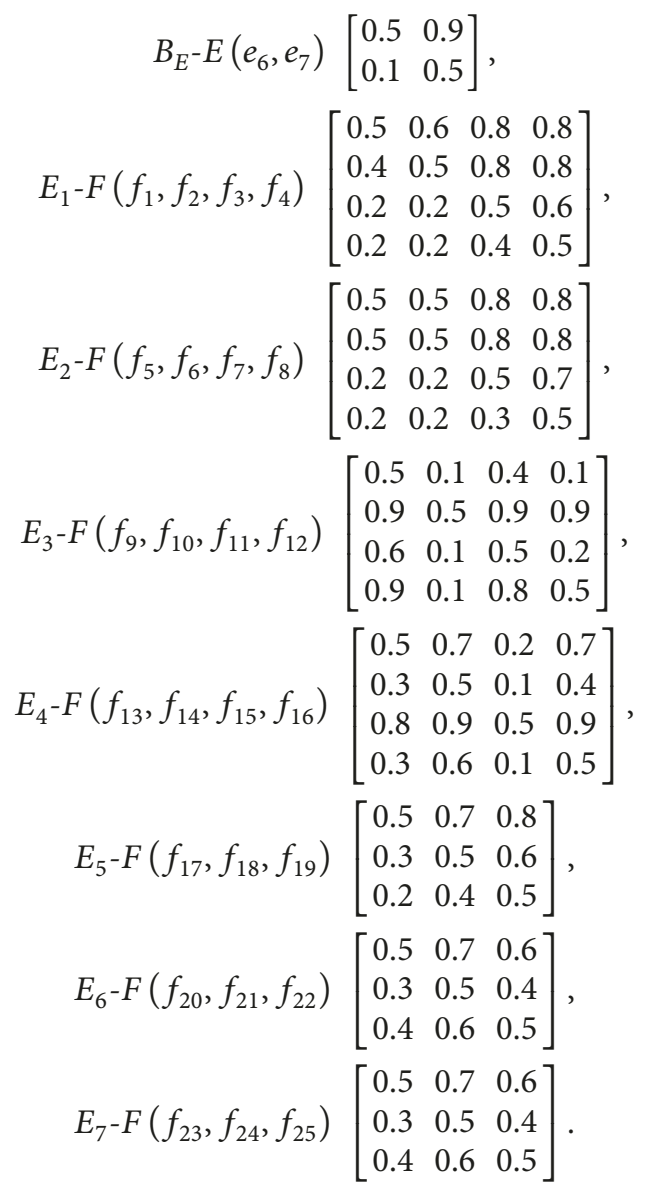

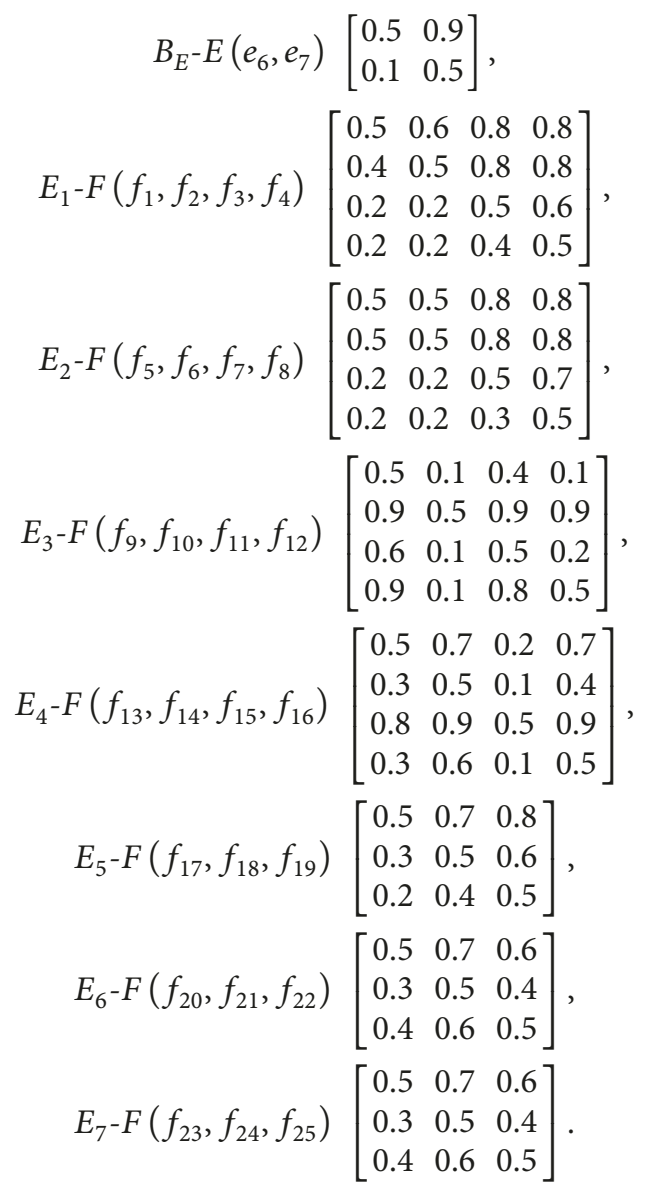

$$
E_{1}-F\left(f_{1}, f_{2}, f_{3}, f_{4}\right)
$$

$$
B_{M}-E\left(e_{3}, e_{4}, e_{5}\right)
$$

$$
B_{E}-E\left(e_{6}, e_{7}\right)
$$$$
\mathbf{w}\left(B_{2}-E\right)=\left[\begin{array}{lllllll}
0 & 0 & 0.411 & 0.411 & 0.178 & 0 & 0
\end{array}\right]^{T} .
$$

$$
\mathbf{w}\left(B_{2}-E\right)=\left[\begin{array}{lllllll}
0 & 0 & 0 & 0 & 0 & 0.637 & 0.363
\end{array}\right]^{T} .
$$

$$
\mathbf{w}\left(E_{1}-F\right)=\left[\begin{array}{lllllllllllllllllllllllll}
0.341 & 0.307 & 0.185 & 0.167 & 0 & 0 & 0 & 0 & 0 & 0 & 0 & 0 & 0 & 0 & 0 & 0 & 0 & 0 & 0 & 0 & 0 & 0 & 0 & 0 & 0
\end{array}\right]^{T} .
$$

$E_{2}-F\left(f_{5}, f_{6}, f_{7}, f_{8}\right)$

$$
\mathbf{w}\left(E_{2}-F\right)=\left[\begin{array}{lllllllllllllllllllllllll}
0 & 0 & 0 & 0 & 0.332 & 0.332 & 0.176 & 0.16 & 0 & 0 & 0 & 0 & 0 & 0 & 0 & 0 & 0 & 0 & 0 & 0 & 0 & 0 & 0 & 0 & 0
\end{array}\right]^{T} .
$$

$E_{3}-F\left(f_{9}, f_{10}, f_{11}, f_{12}\right)$

$$
\mathbf{w}\left(E_{3}-F\right)=\left[\begin{array}{lllllllllllllllllllllllll}
0 & 0 & 0 & 0 & 0 & 0 & 0 & 0 & 0.14 & 0.433 & 0.163 & 0.264 & 0 & 0 & 0 & 0 & 0 & 0 & 0 & 0 & 0 & 0 & 0 & 0 & 0
\end{array}\right]^{T} .
$$

$E_{4}-F\left(f_{13}, f_{14}, f_{15}, f_{16}\right)$

$$
\mathbf{w}\left(E_{4}-F\right)=\left[\begin{array}{lllllllllllllllllllllllll}
0 & 0 & 0 & 0 & 0 & 0 & 0 & 0 & 0 & 0 & 0 & 0 & 0.244 & 0.161 & 0.416 & 0.179 & 0 & 0 & 0 & 0 & 0 & 0 & 0 & 0 & 0
\end{array}\right]^{T} .
$$


$E_{5}-F\left(f_{17}, f_{18}, f_{19}\right)$

$$
\mathbf{w}\left(E_{5}-F\right)=\left[\begin{array}{lllllllllllllllllllllllll}
0 & 0 & 0 & 0 & 0 & 0 & 0 & 0 & 0 & 0 & 0 & 0 & 0 & 0 & 0 & 0 & 0.453 & 0.301 & 0.246 & 0 & 0 & 0 & 0 & 0 & 0
\end{array}\right]^{T} .
$$

$E_{6}-F\left(f_{20}, f_{21}, f_{22}\right)$

$$
\mathbf{w}\left(E_{5}-F\right)=\left[\begin{array}{lllllllllllllllllllllllll}
0 & 0 & 0 & 0 & 0 & 0 & 0 & 0 & 0 & 0 & 0 & 0 & 0 & 0 & 0 & 0 & 0 & 0 & 0 & 0.402 & 0.269 & 0.329 & 0 & 0 & 0
\end{array}\right]^{T} \text {. }
$$

$E_{7}-F\left(f_{23}, f_{24}, f_{25}\right)$

$$
\mathbf{w}\left(E_{5}-F\right)=\left[\begin{array}{lllllllllllllllllllllllll}
0 & 0 & 0 & 0 & 0 & 0 & 0 & 0 & 0 & 0 & 0 & 0 & 0 & 0 & 0 & 0 & 0 & 0 & 0 & 0 & 0 & 0 & 0.402 & 0.269 & 0.329
\end{array}\right] .^{T} .
$$

According to the results of single hierarchy ranking, the total hierarchy ranking of the brittle source of milling blade dorsal positioning surface is obtained.

w

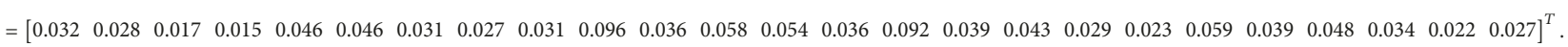

From the results of total hierarchy ranking, it can be seen that the dangerous brittle source is the brittle excitation factors $F 10$ and F15; that is, the cutting speed is too high and the tool wears. Key man-machine-environmental events and factors are determined as the key control points by the dangerous brittle source of milling blade dorsal positioning surface. The out of control of milling blade dorsal positioning surface may be avoided by taking the corresponding measures to ensure the stability of the blade processing. For example, the key factor, cutting speed, is too high, which can be improved by increasing the feed speed and adjusting the cutting parameters to ensure the stability of blade processing and meet the quality requirements. Based on the brittle risk entropy and improved fuzzy analytic hierarchy process (FAHP), the excitation brittle factors of milling blade dorsal positioning surface are analyzed qualitatively and quantitatively, which can ensure the key control points for abnormal process of milling blade dorsal positioning surface.

\section{Conclusion}

This paper presented an approach to determine the key control points of the parts' manufacturing process. Based on this approach, the key control points can be effectively identified and improved to raise the stability of the parts' manufacturing process.
(1) From the characteristics of parts manufacturing, the concept of machining cell was put forward; and the key procedure was determined by analyzing the brittle risk entropy of each machining cell in the parts' manufacturing process.

(2) The human-machine-environment brittleness model of brittle excitation factors of key procedure could be established by analyzing brittle excitation factors from humanmachine-environment.

(3) The brittle sources of key procedure were analyzed and evaluated by improved fuzzy analytic hierarchy process (FAHP) to obtain the dangerous brittle sources of key procedure and the control points corresponding to dangerous brittle source of key procedure in complex parts' manufacturing processes. The stability of the parts' manufacturing process could be raised by improving the key control points effectively.

(4) The key procedure was determined by analyzing the brittle risk entropy of each machining cell in the manufacturing process of an aeroengine blade. And then the control points of key procedure, which needed to improve, were obtained by analyzing and evaluating the brittle source of key procedure. Thereby, the example verified the proposed approach effectively.

The key control points and improvement measures are studied, and the accuracy of this approach is better in 
production efficiency. However, it was necessary to further materialize the key procedure influencing factors in the complex parts' manufacturing process to improve the accuracy and the practicality of this approach.

\section{Conflicts of Interest}

The authors declare that there are no conflicts of interest regarding the publication of this paper.

\section{Acknowledgments}

This project was supported by the National Natural Science Foundation of China (51705392).

\section{References}

[1] G. Zhang, Automatic manufacturing system, China Machine Press, Beijing, 2010.

[2] T. Mo, P. Zhao, R. Duan, and W. Mo, "Modeling and performance analysis of manufacturing execution system based on Petri net," Jisuanji Jicheng Zhizao Xitong/Computer Integrated Manufacturing Systems, CIMS, vol. 21, no. 8, pp. 2063-2071, 2015.

[3] A. M. Patel and A. Y. Joshi, "Modeling and analysis of a manufacturing system with deadlocks to generate the reachability tree using petri net system," in Proceedings of the 2013 International Conference on Design and Manufacturing, IConDM 2013, pp. 775-784, India, July 2013.

[4] H. Hu, Y. Yang, Y. Liu, and C. Chen, "Supervisor design and simplification for Automated Manufacturing Systems using colored Petri nets," in Proceedings of the 2015 IEEE International Conference on Robotics and Automation, ICRA 2015, pp. 38263832, USA, May 2015.

[5] I. Dobson, J. Chen, J. S. Thorp, B. A. Carreras, and D. E. Newman, "Examining criticality of blackouts in power system models with cascading events," in Proceedings of the 35th Annual Hawaii International Conference on System Sciences (HICSS '02), January 2002.

[6] A. A. Fouad, Q. Zhou, and V. Vittal, "System vulnerability as a concept to assess power system dynamic security," IEEE Transactions on Power Systems, vol. 9, no. 2, pp. 1009-1015, 1994.

[7] Q. Zhou, J. Davidson, and A. A. Fouad, "Application of artificial neural networks in power system security and vulnerability assessment," IEEE Transactions on Power Systems, vol. 9, no. 1, pp. 525-532, 1994.

[8] R. Albert, H. Jeong, and A.-L. Barabási, "Error and attack tolerance of complex networks," Nature, vol. 406, no. 6794, pp. 378-382, 2000.

[9] X. F. Wang and J. Xu, "Cascading failures in coupled map lattices," Physical Review E: Statistical, Nonlinear, and Soft Matter Physics, vol. 70, no. 5, Article ID 056113, 2004.

[10] J. Xu and X. F. Wang, "Cascading failures in scale-free coupled map lattices," Physica A: Statistical Mechanics and its Applications, vol. 349, no. 3-4, pp. 685-692, 2005.

[11] Q. Wei, H. Z. Jin, and J. Guo, "Study on the Collapse of Complex System By Using Brittle Link Entropy," Techniques of Automation \& Applications, 2003, Study on the Collapse of Complex System By Using Brittle Link Entropy. Techniques of Automation Applications.
[12] R. Pan-xiang, J. Hong-zhang, and W. Qi, "Brittleness research on complex system based on brittle link entropy," Journal of Marine Science and Application, vol. 5, no. 2, pp. 51-54, 2006.

[13] J. H. Zhang, W. Qi, and G. Jian, Brittle theory and application of complex systems. Xian: Northwestern polytechnical university press, Xian: Northwestern polytechnical university press, 2010.

[14] Y. Qin, L. Zhao, and Y. Yao, "Dynamic quality characteristics modelling based on brittleness theory in complex manufacturing processes," International Journal of Computer Integrated Manufacturing, vol. 24, no. 10, pp. 915-926, 2011.

[15] Y. Qin, L. Zhao, Y. Yao, and D. Xu, "Multistage machining processes variation propagation analysis based on machining processes weighted network performance," The International Journal of Advanced Manufacturing Technology, vol. 55, no. 5-8, pp. 487-499, 2011.

[16] J. Liu, G.-B. Zhang, D.-Y. Li, Y. Li, and B.-M. Qian, "Reliability analysis for multi-state manufacturing system based on brittleness theory," Jisuanji Jicheng Zhizao Xitong/Computer Integrated Manufacturing Systems, CIMS, vol. 20, no. 1, pp. 155-164, 2014.

[17] R. P. Xiang, J. H. Zhang, W. Qi, and Y. L. Mei, "Research on the characteristic of complex system based on brittle link entropy," Electric Machines \& Control, 2005, Research on the characteristic of complex system based on brittle link entropy. Electric Machines Control.

[18] Z. Chang, J. Yang, J. Zhao, and H. Wei, "Optimization of process based on adaptive ant colony algorithm," Chinese Journal of Mechanical Engineering, vol. 48, no. 9, pp. 163-169, 2012.

[19] Y. Xiang, R. Mo, Z. Chang, H. Qiao, and C. Li, "Stability analysis of process route based on weighted network," Mathematical Problems in Engineering, vol. 2015, Article ID 946281, 2015.

[20] H. S. Gao, J. X. Ran, and Y. Q. Sun, Systems Engineering-Theory Practice, vol. 3, Risk Evaluation of Communication Network of Electric Power Based on Improved FAHP. Systems EngineeringTheory Practice, 653-659, 2007.

[21] Z. Geng, Z. Wang, C. Peng, and Y. Han, "A New Fuzzy Process Capability Estimation Method Based on Kernel Function and FAHP," IEEE Transactions on Engineering Management, vol. 63, no. 2, pp. 177-188, 2016.

[22] J. Wang, Y. J. Pang, Z. Y. Yang, and H. ZH, "Application of improved FAHP in evaluation of AUV overall performance," Journal of Shanhai Jiao Tong University, vol. 49, pp. 275-280, 2015.

[23] L.-H. Li and R. Mo, "Production task queue optimization based on multi-attribute evaluation for complex product assembly workshop," PLoS ONE, vol. 10, no. 9, Article ID e0134343, 2015.

[24] N. Kamiyama, "Efficiently constructing candidate set of network topologies," IEICE Transactions on Communications, vol. E96-B, no. 1, pp. 163-172, 2013.

[25] L. Shi, J. Shuai, and K. Xu, "Fuzzy fault tree assessment based on improved AHP for fire and explosion accidents for steel oil storage tanks," Journal of Hazardous Materials, vol. 278, pp. 529538, 2014.

[26] P. Wang, D.-H. Zhang, B. Chen, S. Li, and G.-H. Ma, "Evaluation of multi-process plans based on fuzzy comprehensive evaluation and grey relational analysis," Journal of Aerospace Power, vol. 27, no. 9, pp. 2075-2085, 2012.

[27] X. Ying, M. O. Rong, Z. Chang, and Q. Hu, "Evolution of product module based on complex network brittleness theory," Computer Integrated Manufacturing Systems, vol. 22, 2016. 


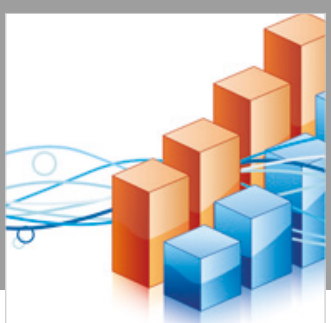

Advances in

Operations Research

\section{-n-m}
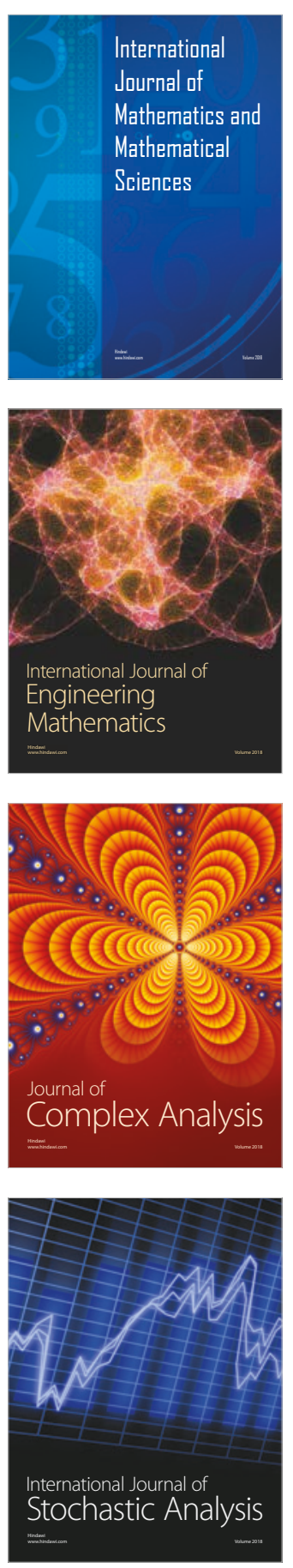
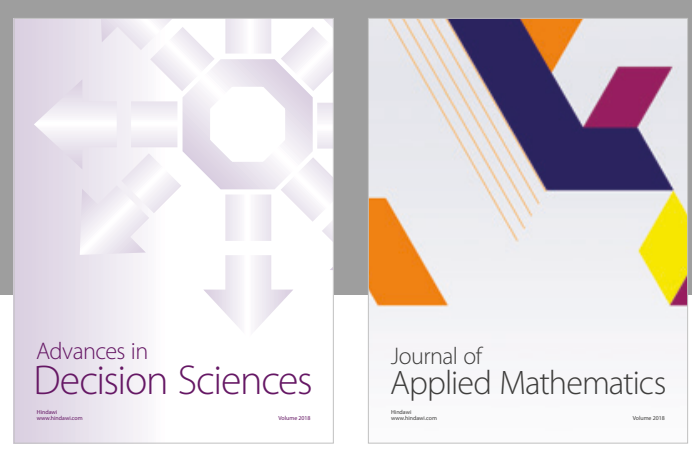

Journal of

Applied Mathematics
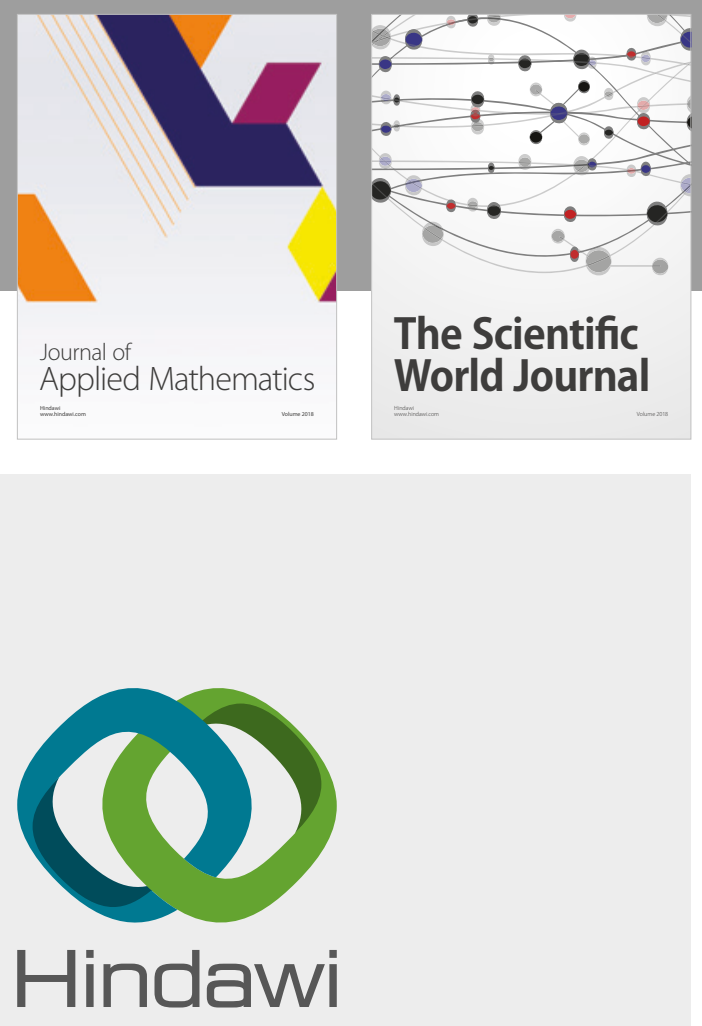

Submit your manuscripts at

www.hindawi.com

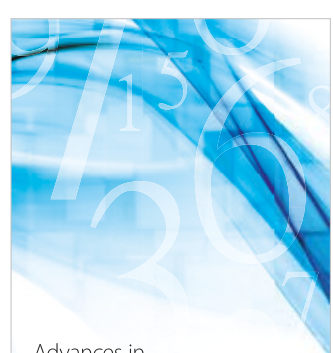

Advances in
Numerical Analysis
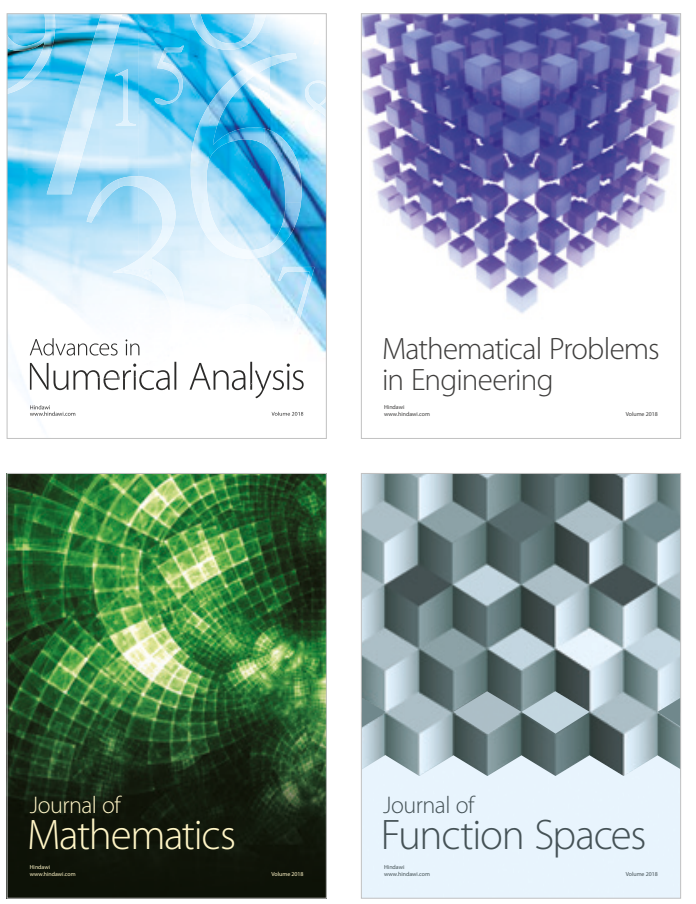

Mathematical Problems in Engineering

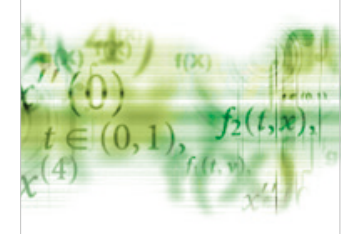

International Journal of

Differential Equations

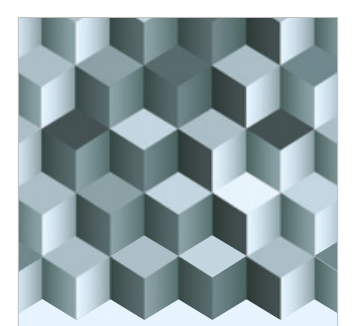

Journal of

Function Spaces

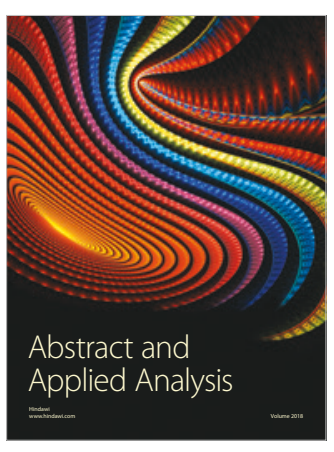

The Scientific

World Journal

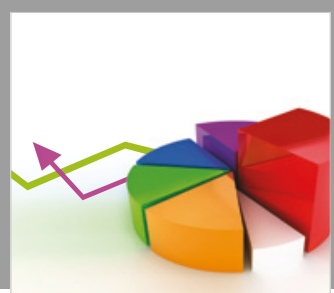

Journal of

Probability and Statistics
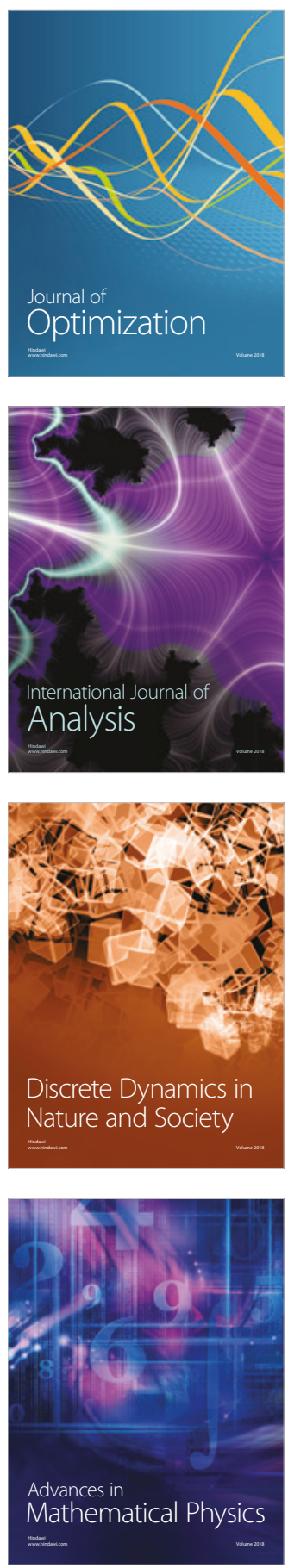